\title{
PSICANÁLISE, CLÍNICA \\ AMPLIADA E DOR FÍSICA: \\ ALGUMAS ARTICULAÇÕES
}

\section{Rodrigo Sanches Peres}

Universidade Federal de Uberlândia

Josiane Cristina Bocchi

Universidade Estadual Paulista "Júlio de Mesquita Filho"
Recebido em: 30/07/2020

$1^{\text {a }}$ revisão em: 11/09/2020

Aceito em: 31/10/2020

\section{RESUMO}

A Psicanálise é capaz de enriquecer a clínica ampliada e, assim, viabilizar a superação de limitações inerentes ao modelo biomédico que se revelam por meio de práticas em saúde voltadas a pacientes que padecem de dor física. O presente estudo possui um duplo objetivo. Em primeiro lugar, buscaremos traçar um breve panorama de tentativas de compreensão da dor física ao longo da história, a fim de contextualizar e problematizar o surgimento e a consolidação do modelo biomédico. Em segundo lugar, discutiremos alguns aportes psicanalíticos para a apreensão teórica da dor física que, a nosso ver, podem gerar contribuições relevantes para a clínica ampliada. Concluímos, com base em formulações freudianas e pós-freudianas, que a dor física, desde diferentes ângulos, ocupa um "lugar" fronteiriço, em contraste com o que sugere o modelo biomédico. Com isso, iluminamos aspectos subjetivos das condições dolorosas que merecem ser levados em conta pelos profissionais de saúde.

Palavras-chave: Dor; clínica ampliada; teoria psicanalítica; saúde. 


\section{PSYCHOANALYSIS, EXTENDED CLINIC, AND PHYSICAL PAIN: SOME ARTICULATIONS}

\section{ABSTRACT}

Psychoanalysis is able to enrich the expanded clinic and, thus, make it possible to overcome limitations inherent to the biomedical model that are revealed through health practices aimed at patients who suffer from physical pain. The present study has a double objective. First, we will seek to outline a brief overview of attempts to understand physical pain throughout history, in order to contextualize and problematize the emergence and consolidation of the biomedical model. Second, we will discuss some psychoanalytical contributions for the theoretical understanding of physical pain that, in our view, can produce relevant contributions to the expanded clinic. We conclude, based on Freudian and Post-Freudian formulations, that physical pain, from different perspectives, occupies a "place" between borders, in contrast to what the biomedical model proposes. Thus, we illuminate subjective aspects of painful conditions that deserve to be taken into account by health professionals.

Keywords: Pain; extended clinic; psychoanalytic theory; health. 


\section{PSICOANÁLISIS, CLÍNICA AMPLIADA Y DOLOR FÍSICO: ALGUNAS ARTICULACIONES}

\section{RESUMEN}

El psicoanálisis es capaz de enriquecer la clínica ampliada y, de este modo, posibilitar la superación de limitaciones inherentes al modelo biomédico que se revelan mediante prácticas en salud dirigidas a pacientes que padecen de dolor físico. Este trabajo posee un doble objetivo. En primer lugar, procuraremos trazar un breve panorama de tentativas de comprensión del dolor físico a lo largo de la historia, a fin de contextualizar y problematizar el surgimiento y la consolidación del modelo biomédico. En segundo lugar, discutiremos algunos aportes psicoanalíticos para la aprehensión teórica del dolor físico que, a nuestro juicio, pueden generar contribuciones relevantes para la clínica ampliada. Concluimos, con base en formulaciones freudianas y posfreudianas, que el dolor físico, desde diferentes ángulos, ocupa un "lugar" fronterizo, en contraste con lo que sugiere el modelo biomédico. Así, iluminamos aspectos subjetivos de las condiciones dolorosas que merecen ser tenidos en cuenta por los profesionales de la salud.

Palabras clave: Dolor; clínica ampliada; teoría psicoanalítica; salud. 


\section{INTRODUÇÃO}

Como observou Le Breton (1995), a dor física se afigura como a experiência mais compartilhada pelos seres humanos, pois ninguém pode dela escapar por toda a vida. O referido autor ainda acrescentou que, de maneira provisória ou definitiva, o indivíduo que padece de uma condição dolorosa tem sua existência colocada abruptamente em suspensão, pois se vê submetido a uma espécie de possessão corrosiva. Mais concretamente, a dor física é reconhecida como um importante problema de saúde pública contemporâneo, não somente porque afeta um número expressivo de pessoas e leva boa parte delas a acionar serviços de saúde em busca de alívio, mas também porque tende a gerar intenso sofrimento (Carr, 2016).

Por séculos, o conhecimento a respeito da dor física não foi suficiente para fazerIhe frente de modo efetivo. Porém, na atualidade há diversas estratégias terapêuticas disponíveis, farmacológicas e não-farmacológicas. Ou seja: os seres humanos deixaram de ser totalmente impotentes diante da dor física. Não obstante, cada vez mais pessoas são afetadas por condições dolorosas e, mesmo quando inexiste lesão orgânica subjacente, a cronificação ${ }^{1}$ é relativamente comum. Tal fato tem sido associado à emergência de novos hábitos de vida e ao aumento global da longevidade (Bourke, 2014).

Por outro lado, é possível propor que a escalada da dor física em nossos dias igualmente reflete as limitações do modelo biomédico ainda hegemônico no campo da saúde. Isso porque, em consonância com Lima e Trad (2008), o modelo biomédico é marcado por um viés pragmático e mecanicista, em função do qual os aspectos objetivos da dor física - bem como do processo saúde-doença como um todo - são claramente privilegiados em detrimento dos aspectos subjetivos. Consequentemente, as condições dolorosas são tomadas por muitos profissionais de saúde como entidades independentes das pessoas que as vivenciam, o que, como advertiram as referidas autoras, fomenta tratamentos ineficazes, e até mesmo iatrogênicos.

A clínica ampliada, concebida como instrumento de atenção integral em saúde, se propõe a contemplar tanto os aspectos objetivos quanto os aspectos subjetivos do processo saúde-doença, de acordo com Campos (2015). Por essa razão, preconiza que os profissionais de saúde devem centrar suas ações no sujeito, e não apenas em sua enfermidade. O referido autor apresentou tal ponto de vista ao discutir a relevância da clínica ampliada na atenção primária à saúde. Todavia, não resta dúvida de que os princípios da clínica ampliada são aplicáveis a todos os níveis de atenção em saúde. Parece-nos razoável cogitar que, sendo empregados especificamente para nortear práticas em saúde voltadas a pacientes que padecem de dor física, tais princípios podem viabilizar a superação das limitações inerentes ao modelo biomédico. 
Há de se considerar ainda que, acompanhando Campos (2012), a Psicanálise é capaz, de muitas formas, de enriquecer a clínica ampliada, uma vez que, dentro ou fora do setting psicanalítico tradicional, fundamenta práticas em saúde que priorizam a escuta do sujeito em sua singularidade. Em virtude do exposto, o presente estudo possui um duplo objetivo. Em primeiro lugar, buscaremos traçar um breve panorama de tentativas de compreensão da dor física ao longo da história, a fim de contextualizar e problematizar o surgimento e a consolidação do modelo biomédico. Em segundo lugar, discutiremos alguns aportes psicanalíticos para a apreensão teórica da dor física que, a nosso ver, podem gerar contribuições relevantes para a clínica ampliada.

Antecipamos que serão abordadas aqui formulações estabelecidas por Freud em torno das noções de pseudo-pulsão e trauma, passando por suas teses sobre o luto e a melancolia. Adicionalmente, nos ocuparemos das ideias de Marty concernentes ao conceito de mentalização. Dessa maneira, operacionalizaremos um recorte teórico bastante específico, por meio do qual revisitaremos certas premissas freudianas clássicas e abarcaremos alguns de seus desenvolvimentos contemporâneos, estabelecidos, no caso, no âmbito da chamada Escola Psicossomática de Paris. Buscaremos, assim, colocar em relevo o fato de que, desde vários ângulos, a dor física se situa em um "lugar" fronteiriço, sendo que, devido à essa característica, seu manejo clínico demanda o diálogo entre saberes provenientes de diferentes disciplinas.

\section{DESENVOLVIMENTO}

\section{DA VISÃO MÁGICO-RELIGIOSA AO MODELO BIOMÉDICO DA DOR FÍSICA}

Inicialmente, julgamos interessante mencionar que, na Mesopotâmia, por volta de 3000 a.C., acreditava-se que a dor física resultava da invasão do corpo por espíritos demoníacos. Portanto, sacrifícios e exorcismos eram frequentemente praticados pelos sumérios visando à cura de condições dolorosas. Em contrapartida, as propriedades analgésicas de extratos de papoula e emplastros de sálvia já eram conhecidas (Teixeira \& Okada, 2009). De forma semelhante, no Egito Antigo, entre 1000 a.C. e 1500 a.C., o emprego de vegetais narcóticos era comum, mas prevalecia uma visão mágico-religiosa da dor física (Sabatowski, Schäfer, Kasper, Brunsch \& Radbruch, 2004).

Na Grécia Antiga, o filósofo Aristóteles (384-332 a.C.) concebia a dor física, basicamente, como um tipo diferenciado de emoção, como sublinhou Le Breton (1995). Já Hipócrates (460-377 a.C.), o pai da Medicina ocidental, atrelava a origem das condições dolorosas a alterações do equilíbrio do organismo, sendo que, para corrigi-las, preconizava tanto terapêuticas naturalísticas quanto procedimentos cirúrgicos rudimentares (Bourke, 2014). No mundo oriental, o advento do budismo, no século $V$ a.C., fez com que a dor física passasse a ser associada à frustração dos desejos e, consequentemente, a alma foi designada como sua fonte pelos indianos (Pérez-Cajaraville, Abejón, Ortiz \& Pérez, 2005). 
Durante o Império Romano, o médico e filósofo Galeno (131-200) afirmou, com o apoio de seus estudos fisiológicos, que a dor física derivaria de ações relativas apenas ao organismo, nomeadamente à ação do sistema nervoso central no que tange à captação de impressões externas e à transformação das mesmas em percepções conscientes (Teixeira \& Okada, 2009). Contudo, na Idade Média, as condições dolorosas, como desdobramento da influência exercida pela Igreja Católica sobre todas as questões humanas, voltaram a ser atribuídas a punições divinas, as quais supostamente seriam implementadas em favor da salvação da alma, segundo Lobato (2010). Destarte, qualquer meio que pudesse aliviar a dor física era desencorajado por tal instituição.

É notório que, nos séculos XV e XVI, a ciência ganhou novo alento com o Renascimento. Na esteira desse movimento, Leonardo da Vinci (1452-1519) empreendeu uma minuciosa descrição do corpo para embasar suas obras como pintor e escultor. Seus estudos anatômicos, inclusive, o levaram a hipotetizar que a medula espinhal seria responsável pela condução dos estímulos nocivos ao cérebro, como informam Pérez-Cajaraville et al (2005). No século seguinte, o filósofo francês René Descartes (1596-1650), radicalizando o racionalismo renascentista, inaugurou uma concepção dualista ao sugerir que os seres humanos seriam formados por duas partes básicas e distintas entre si: mente e corpo.

O pensamento cartesiano, emblemático da chamada Idade da Revolução Científica, engendrou a reificação do corpo ao estimular analogias em função das quais os seres humanos passaram a ser comparados a máquinas, como observou Barros (2002). Outrossim, Descartes postulou que a dor física seria produzida por meio da transmissão de sensações provindas do exterior diretamente ao cérebro, pelo que equivaleria a uma resposta dos filamentos corporais a estímulos nocivos (Bourke, 2014), bem como distinguiu a dor física dos sentimentos que poderiam acompanhá-la, dentre os quais a raiva e a tristeza, circunscrevendo-os à mente.

Ideias naturalistas receberam destaque novamente durante o lluminismo, vigente no século XVIII, de forma que as condições dolorosas passaram a ser encaradas como uma espécie de punição da natureza (Teixeira \& Okada, 2009). Ocorre que a dor física era vista como fruto do desrespeito às regras naturais do corpo e da vida. Não obstante, o naturalismo iluminista pode ser associado à criação da morfina, já no início do século seguinte, uma vez que foi viabilizada mediante o isolamento de um alcaloide a partir da resina da papoula (Sabatowski et al, 2004).

O século XIX, com a ascensão do cientificismo, testemunhou uma série de descobertas médicas, as quais subsidiaram, por exemplo, o refinamento das informações disponíveis sobre as sensações em geral e sobre a dor física em específico (Teixeira \& Okada, 2009). A Medicina ocidental, então, reorganizou-se gradativamente, apoiando-se na concepção dualista de Descartes, o que culminou na consolidação do modelo biomédico no século XX. Nessa conjuntura, passou a imperar uma lógica unicausal que ensejou o obscurecimento de novas inteligibilidades sobre o processo saúde-doença que - a exemplo daquela oriunda 
dos pressupostos psicanalíticos - já à época colocavam em relevo seus aspectos subjetivos (Barros, 2002).

Nas primeiras décadas do século $X X$, como um dos reflexos da hegemonia do modelo biomédico, foram criadas teorias fisiológicas amparadas em novos achados sobre a transmissão nervosa que levavam em conta apenas a faceta orgânica da dor física, de acordo com Lima e Trad (2008). Porém, as referidas autoras acrescentam que se constataria, paulatinamente, que a dor física sobretudo quando se torna crônica - escapa ao modelo biomédico. Tal constatação, inclusive, se depreende da definição mais amplamente aceita na atualidade, segundo a qual a dor física é enquadrada como um fenômeno subjetivo e multidimensional (Task Force on Taxonomy of the International Association for the Study of Pain, 1994, p. 210).

Diante do exposto, é possível notar que o modo como ainda se compreende a dor física na atualidade à luz do modelo biomédico possui raízes históricas diretamente vinculadas ao enfoque organicista defendido por Galeno no Império Romano, bem como é tributária da concepção dualista introduzida por Descartes como corolário do racionalismo renascentista. A identificação dessas raízes históricas demarca alguns dos motivos pelos quais são tão frequentes, nos dias de hoje, práticas em saúde que se revelam fragmentadas, impessoais e, consequentemente, ineficientes. Todavia, como procuraremos demonstrar a seguir, a Psicanálise, por meio de suas contribuições à clínica ampliada, é capaz de auxiliar a reverter tal cenário.

\section{PSEUDO-PULSÃO, MELANCOLIA E DOR FÍSICA}

A princípio, é importante esclarecer que Freud não tematizou a dor física de modo direto. Porém, o fez indiretamente ao tratar de outros assuntos, como se vê em Repressão $o^{2}$. No texto em questão, Freud (1915a/1996) defendeu que a dor poderia ser concebida como uma espécie de pseudo-pulsão, na medida em que eventualmente se originaria de um processo de internalização de estímulos externos que resultaria na implementação de uma fonte de excitação contínua. Ressalte-se que, ao desenvolver tal argumentação, o referido autor não diferenciou a dor física da dor psíquica, o que sugere que ambas possuiriam uma importante dimensão subjetiva, determinada pela natureza do processo de internalização mencionado.

Já em Os instintos e suas vicissitudes, lê-se que "as sensações de dor, como outras sensações desagradáveis, beiram a excitação sexual e produzem uma condição agradável, em nome da qual o sujeito, inclusive, experimentará de boa vontade o desprazer da dor" (Freud, 1915b/1996, p. 134). Todavia, no masoquismo, fruir-seia a excitação sexual concomitante à dor e não a dor propriamente dita, ao passo que o sádico vivenciaria algo semelhante ao infligir dor a outra pessoa, ainda segundo Freud. Ademais, o escrito em pauta demarca que a pulsão se situaria no limite entre o somático e o psíquico. Logo, enquanto pseudo-pulsão, a dor igualmente ocuparia um "lugar" fronteiriço. 
Em Luto e melancolia, Freud (1917[1915]/1996) postulou que, no enlutado, haveria uma "disposição dolorosa" que seria ausente no melancólico. Ao fazê-lo, Freud aparentemente aludiu sobretudo à dor psíquica, na medida em que o luto se expressa essencialmente no plano mental. Porém, o luto e a melancolia compartilhariam uma série de características, pois se afigurariam como reações à perda de um objeto libidinalmente investido ${ }^{3}$ e envolveriam um desânimo profundo, um abandono generalizado do interesse pelo mundo externo e uma significativa diminuição das atividades. A melancolia, para o referido autor, somente teria como traço distintivo - do ponto de vista sintomático-descritivo uma perturbação da autoestima que se expressaria por meio de autorrecriminação e expectativa delirante de punição.

No texto em questão, Freud (1917[1915]/1996) ainda deu a entender que na melancolia não existiria a referida "disposição dolorosa" porque o sujeito prosseguiria investindo sua libido no objeto perdido. Entretanto, o faria inconscientemente, catexizando o próprio ego à custa de uma identificação narcísica com o objeto perdido. O enlutado, em contraste, se engajaria no chamado "trabalho de luto", descatexizando o objeto perdido, em um primeiro momento, e catexizando um novo objeto, em um segundo momento. Portanto, entendemos que as formulações freudianas delineadas em Luto e melancolia indicam que as vicissitudes do trabalho de luto tornariam o enlutado mais propenso à dor psíquica. O melancólico, em contrapartida, seria mais suscetível à dor física, especialmente crônica, dado que se recusaria a retirar sua libido do objeto perdido.

Cabe aqui relembrar que os planos mental e somático, no pensamento freudiano, não podem ser dissociados por completo e não apenas no que diz respeito à dor. Todavia, em escritos redigidos após o advento da segunda tópica, é reafirmada a possibilidade de se circunscrever algumas diferenças entre a dor física e a dor psíquica. Inibições, sintomas e ansiedade é uma obra emblemática neste sentido, pois nela o autor afirmou que a "transição" da dor física para a dor psíquica "corresponde a uma mudança na catexia narcísica para a catexia objetal" (Freud, 1926[1925]/1996, p. 166). Tal afirmação, ademais, nos parece consubstanciar a existência de uma vertente melancólica na dor física - sobretudo crônica esboçada anteriormente em Luto e melancolia, como já propusemos. O uso do termo "transição", especificamente, aparenta reforçar o "lugar" fronteiriço ocupado pela dor física.

Há de se sublinhar que, em Inibições, sintomas e ansiedade, Freud (1926[1925]/1996) se perguntou em que circunstâncias a separação de um objeto produziria angústia, luto ou dor. Desse modo, reconheceu definitivamente a dor como uma das reações possíveis à perda de um objeto libidinalmente investido, agora ao lado do luto e da angústia. Considerando-se o contexto, aparentemente o referido autor aludiu à dor física ao lançar tal pergunta, o que pode ser considerado mais um indício da existência de uma estreita relação entre a melancolia e a dor física. 
Outrossim, Freud asseverou, ainda em Inibições, sintomas e ansiedade, que a dor seria uma "reação real" a uma perda objetal significativa, sendo que, ao que tudo indica, novamente fez menção à dor física. Consequentemente, compreendemos que a dor física, em certos casos, se revestiria de certa crueza determinada pela carência de recursos psíquicos capazes de preservar a concretude do corpo dos efeitos da privação de um objeto libidinalmente investido. Tal ponto de vista foi aprofundado posteriormente por Marty por meio do conceito de mentalização, como veremos mais adiante.

\section{TRAUMA E DOR FÍSICA}

A relação entre trauma e dor física foi mais claramente formulada no pensamento freudiano às expensas dos avanços que conduziram à criação da segunda tópica. Em Além do princípio do prazer (Freud, 1920/1996), nomeadamente, despontam articulações interessantes a respeito dos "choques" que podem ser provocados no aparelho mental por perigos externos. Tais articulações foram desenvolvidas nos termos do segundo dualismo pulsional e com base no reconhecimento do papel da economia narcísica para a depuração da noção de trauma. Ademais, o conceito de narcisismo foi empregado como subsídio teórico para explicar o processo de ligação do excesso traumático e alguns derivativos da compulsão à repetição que podem desempenhar uma função importante na formação de condições dolorosas, na medida em que alteram a tessitura do ego e as relações objetais.

Mas é preciso sublinhar que a concepção quantitativa da dor física apresentada em Além do princípio de prazer reacendeu a ideia de que a estimulação advinda de eventos reais se transformaria em uma excitação interna contínua e passaria a atuar desde o âmago do aparelho mental como se fosse uma pulsão, exercendo efeitos sobre a distribuição da libido no ego e no corpo. Tal perspectiva ensejou um aprofundamento das hipóteses freudianas sobre o trauma por conta, principalmente, da introdução de inovações teóricas sobre o narcisismo e o masoquismo. Todavia, no texto em questão, Freud (1920/1996) afirmou que um trauma consistiria, em essência, na ruptura de uma barreira que, anteriormente, se mostrara eficaz contra estímulos externos.

A dor física portanto, seria uma consequência do rompimento do "escudo protetor" em uma área limitada, acontecimento que geraria excitações que, desde uma região periférica, se dirigiriam para o interior do aparelho mental (Freud, 1996/1920). Uma tese semelhante havia sido apresentada originalmente em Projeto para uma psicologia científica, obra na qual Freud (1950[1895]/1996), em uma linguagem fundamentalmente neurológica, relacionou a dor - sem especificação clara quanto à sua natureza física ou psíquica - a um fracasso de dispositivos biológicos de proteção que poderia ser descrito como o "protótipo normal" de um processo patológico.

Somando-se a isso, na teorização metapsicológica da década de 1920 a dor física foi associada a um modo de defesa narcísica que, ao falhar, geraria perturbações análogas àquelas presentes nas neuroses traumáticas e em outras afecções nas 
quais - como na hipocondria e na melancolia - a "indisposição subjetiva" é intensa devido a um conflito egóico. O referido autor asseverou também que, nessas perturbações, "o ônus principal de sua causação parece repousar sobre o fator da surpresa, do susto" (Freud, 1920/1996, p. 23). De tal tese depreende-se que um trauma procederia da falta de prontidão para a angústia ou para o medo, o que ocorreria em situações nas quais o sujeito entra em contato com um perigo sem estar minimamente preparado.

Ainda em Além do princípio de prazer, Freud (1920/1996) sustentou que, quando situações dessa natureza também provocam um dano físico importante, a exemplo do que é comum em uma ampla gama de acidentes "mecânicos", o surgimento de uma neurose traumática torna-se pouco provável. A teoria do narcisismo foi acionada pelo referido autor para elucidar esse fato, partindo-se da premissa de que um "choque" liberaria uma quantidade de excitação que influenciaria abruptamente a distribuição libidinal. Não obstante, a existência de uma lesão orgânica ocasionada por "força mecânica" desencadearia um superinvestimento narcísico que possibilitaria a ligação dessa quantidade de excitação, operando no sentido contrário à eclosão de uma neurose traumática.

A instalação de condições dolorosas desvinculadas de lesão orgânica, por sua vez, refletiria a premência de uma intensificação da catexização nos arredores da região periférica do aparelho mental em que houve a ruptura provocada pelo "choque", o que levaria ao empobrecimento de funções psíquicas. Assim, acompanhando Freud (1920/1996), pensamos que um dano físico tem condições de oferecer, ainda que provisoriamente, um campo de objetalização para o "choque", exercendo, portanto, um efeito regulador sobre o mesmo, inclusive a ponto de minimizar seu caráter traumático. Adicionalmente, questionamos se a dor física crônica, em contraste, poderia ocupar o lugar de um objeto ou do próprio ego.

Se sim, a dor física crônica, a nosso ver, constituiria uma forma de existência possível, o que, no limite, permite a demarcação de tendências masoquistas. Mas, tipicamente, a dor física crônica não parece estar a serviço da obtenção de prazer no sofrimento. Logo, as referidas tendências masoquistas seriam concernentes a uma modalidade masoquismo que não resulta de um retorno do sadismo sobre a própria pessoa, mas, sim, de uma fusão pulsional por meio do qual uma parcela da pulsão de morte permanece interna, amenizada por uma parcela da pulsão de vida. Essa fusão, originalmente concebida por Freud (1924/1996) em O problema econômico do masoquismo, fomenta, de modo compulsivo, a necessidade de punição, o que legitima nossas conjecturas.

\section{MENTALIZAÇÃO E DOR FÍSICA}

De acordo com um dos postulados da Escola Psicossomática de Paris, o excesso de tensões - quer sejam endógenas ou exógenas - mobiliza inconscientemente, nesta sequência, o aparelho mental, o aparelho sensório-motor e, em último caso, a via somática. Em A psicossomática do adulto, Marty (1993) defendeu tal linha de raciocínio ao afirmar que, por meio de uma ampla gama de comportamentos, o 
aparelho sensório-motor é capaz de proporcionar uma válvula de escape de eficácia temporária em face da necessidade de escoamento das tensões que não puderam ser tramitadas psiquicamente. Quando tal expediente se revela inoperante, as tensões se propagariam até atingir o corpo em sua materialidade, degenerando, como consequência, funções orgânicas cada vez mais importantes.

Assim, o referido autor salienta a existência de uma unidade entre o corpo e a mente cuja funcionalidade dependeria do conjunto de representações psíquicas de cada sujeito. Em obras como A psicossomática do adulto, Marty (1993) empregou o conceito de mentalização justamente para designar esse conjunto e realçar seu caráter dinâmico, bem como defendeu que as representações psíquicas se afiguram como evocações de percepções inscritas no aparelho mental às expensas de um complexo processo de apreensão e, sobretudo, de reconstrução dos estímulos aos quais o indivíduo é submetido durante a vida. Logo, as representações psíquicas podem apresentar variações qualitativas e quantitativas ao longo do tempo em uma mesma pessoa.

Uma "boa mentalização", conforme Marty (1993), se caracteriza por representações psíquicas que, sendo apropriadas em termos quantitativos e qualitativos, se revelam prenhes de conotações afetivas. Por essa razão, constituem cadeias associativas capazes de subsidiar a tramitação das tensões no aparelho mental. A quantidade representacional depende, fundamentalmente, do acúmulo de representações psíquicas que se inicia na primeira infância e se mantém vigente por todo o ciclo vital, ao passo que a qualidade representacional advém da evocação e da ligação de representações psíquicas prévias, inclusive oriundas de épocas distintas, como consta também de $A$ psicossomática do adulto.

Ressalte-se que, acompanhando a terminologia estabelecida na primeira tópica, Marty (1976), em Les mouvements individuels de vie et de mort, identificou o préconsciente como a sede das representações psíquicas. Adicionalmente, defendeu que sua organização pode ser afetada por lacunas fundamentais, correlativas de problemas nas etapas iniciais do desenvolvimento causados pelo desempenho inapropriado da função materna, ou por lacunas secundárias, derivadas da utilização exacerbada de mecanismos de defesa como a repressão. No tocante às representações psíquicas e suas respectivas conotações afetivas, a lacunas fundamentais produziriam insuficiências quantitativas e qualitativas, sendo que as lacunas secundárias gerariam somente indisponibilidades. Destarte, uma "má mentalização" estaria associada a lacunas fundamentais do pré-consciente e favoreceria o acionamento da via somática diante do excesso de tensões.

Em A psicossomática do adulto, Marty (1993) aprofundou essa argumentação ao asseverar que, de modo geral, uma pessoa dotada de uma "boa mentalização" experimenta, como desdobramento da perda de um objeto libidinalmente investido, uma indisponibilidade de representações psíquicas que possivelmente não inviabilizará seu engajamento no trabalho de luto. A via somática, na pior das hipóteses, apenas substituiria pontualmente o aparelho mental e o aparelho 
sensório-motor, o que resultaria em sintomas físicos leves e passageiros. Em contraste, uma pessoa dotada de uma "má mentalização" e que sofre uma perda objetal significativa tende, por conta da limitação de sua capacidade de elaboração psíquica, a descompensações mais graves no que diz respeito ao funcionamento somático.

Compreendemos que, muitas vezes, descompensações dessa natureza podem estar na origem de condições dolorosas, principalmente quando ocorre cronificação. Devemos advertir que, ao lançar tal hipótese, estamos promovendo uma expansão da teorização de Marty, pois o mesmo não associou explicitamente a dor física à "má mentalização". Contudo, a nosso ver tal expansão encontra respaldo, por um lado, nas aproximações que, a partir de Freud, estabelecemos anteriormente entre a melancolia e a dor física, bem como, por outro lado, na concepção de traumatismo ${ }^{4}$ adotada no âmbito da Escola Psicossomática de Paris. Isso porque, em A psicossomática do adulto, Marty (1993) afirmou que se configura um traumatismo quando as possibilidades de adaptação de um indivíduo são ultrapassadas, favorecendo, consequentemente, a emergência de uma miríade de sintomas físicos mediante o acionamento da via somática.

Logo, o escrito em pauta enfatiza que um traumatismo se define a posteriori, o que demarca um nítido alinhamento às premissas freudianas sobre o tema. Não obstante, Marty (1993) elencou como exemplos de traumatismos os seguintes eventos reais:

perda de um ente querido, de uma função profissional ou familiar, perda de uma relação sexual ou amizade, perda de um grupo ao qual se pertença, mas também perda de um sistema de vida anterior, perda de uma liberdade, perda de uma função fisiológica (menopausa, amputação, por exemplo) ou mental (no envelhecimento, por exemplo), de um funcionamento sexual, de uma atividade esportiva, perda de um projeto de trabalho ou de férias, mas também figuração fantasmática, por ocasião de um acontecimento apenas sensível, de uma das perdas anteriores ( $p$. 45).

Em que pese qualquer mal-entendido que possa ser causado por essa listagem, Marty sustenta que o valor traumático de um evento é conferido pela intolerância individual às tensões por ele suscitadas. Isso fica claro em Les mouvements individuels de vie et de mort, publicação na qual lê-se que "a perda de um ente próximo pode não ser mais traumatizante, em um indivíduo adulto, em um dia qualquer, do que para outro, por exemplo, o sentimento provocado pela passagem da poeira por um raio de sol" (Marty, 1976, p. 102, tradução nossa). Nos parece razoável propor que tal ponto de vista, ao situar um traumatismo no intricado interjogo que se estabelece entre a realidade interna e a realidade externa a partir da capacidade de elaboração psíquica de cada um, referenda, desde outro ângulo, o "lugar" fronteiriço da dor física. 


\section{CONSIDERAÇõES FINAIS}

O mapeamento de algumas tentativas de compreensão da dor física ao longo da história, conforme sucintamente executado no presente estudo, sinaliza que o modelo biomédico se ancora em certezas racionais acerca da natureza humana que foram estabelecidas há séculos e se mostram, no mínimo, questionáveis em face da complexidade que, como se sabe na atualidade, é característica do processo saúde-doença. Os aportes psicanalíticos aqui abordados evidenciam que são infrutíferas as tentativas inspiradas no modelo biomédico de se estabelecer uma relação de total exterioridade entre qualquer sujeito e a dor física que o acomete.

Mais precisamente, procuramos salientar que as formulações freudianas e pósfreudianas priorizadas nesta oportunidade nos permitem, de acordo com diferentes perspectivas, posicionar a dor física em um "lugar" fronteiriço. Isso, principalmente, porque a tipificamos como um fenômeno dotado de uma faceta mental e uma faceta orgânica que não podem ser apartadas totalmente. Outrossim, realçamos tanto a vertente melancólica quanto a dimensão traumática da dor física e, consequentemente, sua capacidade de se transfigurar em dor psíquica quando da conversão de uma catexia narcísica em uma catexia objetal ou até mesmo de ser evitada mediante a adequada tramitação das tensões no aparelho mental possibilitada por uma "boa mentalização". Adicionalmente, conjecturamos que a dor física crônica pode refletir tendências masoquistas engendradas pela fusão da pulsão de vida com a pulsão de morte.

Portanto, o presente estudo ilumina aspectos subjetivos das condições dolorosas que, em prol da superação do reducionismo biológico fomentado pelo modelo biomédico, merecem ser levados em conta pelos profissionais de saúde. Em consonância com os princípios da clínica ampliada, tais aspectos subjetivos devem ser contemplados juntamente com aspectos objetivos tematizados por outras disciplinas, até mesmo para que não venha a se estabelecer nenhuma espécie de reducionismo psicológico. Faz-se necessário sublinhar, a propósito, que a Psicanálise sempre renunciou a qualquer pretensão de completude, já que, desde suas origens, se mostrou aberta ao diálogo com os mais variados saberes.

Justamente por essa razão, compreendemos que seria descabido propor, com base em aportes psicanalíticos, um protocolo a ser seguido nas práticas em saúde voltadas a pacientes que padecem de dor física. A nosso ver, é possível unicamente pensar em indicações gerais. Nesses termos, julgamos pertinente recomendar que os profissionais de saúde não tratem a dor física como um mero sintoma a ser erradicado, pois fazê-lo pode implicar em um silenciamento que tende a se revelar insustentável. Em contraste, sugerimos uma abertura - mediante a valorização da escuta - às múltiplas significações das quais a dor física pode se revestir como reflexo das singularidades de cada sujeito. 
Adicionalmente, advertimos, com base nas discussões em torno da noção de trauma veiculadas no presente estudo, que a investigação de perdas objetais significativas vivenciadas pelos pacientes podem proporcionar pistas relevantes para a compreensão de fatores relacionados à eclosão e à manutenção da dor física. Porém, os profissionais de saúde que se dedicarem a tal tarefa devem levar em conta que, como a Psicanálise nos ensina, um trauma se define pela incapacidade de um determinado sujeito assimilá-lo mentalmente e, assim, sua identificação depende de fatores absolutamente individuais. Tal ressalva nos parece pertinente a julgar pelo fato de que a noção de trauma muitas vezes é utilizada no campo da saúde com uma conotação determinista potencializada pelo pragmatismo inerente ao modelo biomédico, o qual, além disso, acaba por tomar muitas experiências humanas como signo de (psico)patologias que deveriam ser eliminadas a todo custo, pois são equivocamente rotuladas apenas como disfunções ou prejuízos.

\section{REFERÊNCIAS}

Barros, J. A. C. (2002). Pensando o processo saúde doença: A que responde o modelo biomédico? Saúde e Sociedade, 11(1), 67-84. https://doi.org/10.1590/S0104-12902002000100008

Bourke, J. (2014). The story of pain: From prayer to painkillers. Oxford: Oxford University Press.

Campos, D. T. F. (2012). O cuidado e o sujeito: Questões acerca da clínica ampliada. In M. Winograd \& M. Souza (Orgs.), Processos de subjetivação, clínica ampliada e sofrimento psíquico (pp. 3348). Rio de Janeiro, RJ: Cia. de Freud.

Campos, G. W. S. (2015). Possibilidades de uma clínica do sujeito na atenção primária à saúde. In R. M. Volich, W. Ranña \& M. E. P. Labaki (Orgs.), Psicossoma V: Integração, desintegração e limites (pp. 447-470). São Paulo, SP: Casa do Psicólogo.

Carr, D. B. (2016). "Pain is a public health problem": What does that mean and why should we care? Pain Medicine, 17(4), 626-627. https://doi.org/10.1093/pm/pnw045

Freud, S. (1996). Projeto para uma psicologia científica (J. L. Meurer, Trad.). In J. Salomão (Org.), Edição standard brasileira das obras psicológicas completas de Sigmund Freud (vol. 1, pp. 347-468) Rio de Janeiro, RJ: Imago. (Trabalho original publicado em 1950[1895]).

Freud, S. (1996). Repressão (Britto, T. O., Britto, P. H., \& Oiticica, C. M., Trads.). In J. Salomão (Org.) Edição standard brasileira das obras psicológicas completas de Sigmund Freud (vol. 14, pp. 151-162). Rio de Janeiro, RJ: Imago. (Trabalho original publicado em 1915a).

Freud, S. (1996). Os instintos e suas vicissitudes (Britto, T. O., Britto, P. H., \& Oiticica, C. M., Trads.). In: J. Salomão (Org.), Edição standard brasileira das obras psicológicas completas de Sigmund Freud (vol. 14, pp. 123-144). Rio de Janeiro, RJ: Imago. (Trabalho original publicado em 1915b).

Freud, S. (1996). Luto e melancolia (Britto, T. O., Britto, P. H., \& Oiticica, C. M., Trads.). In J. Salomão (Org.), Edição standard brasileira das obras psicológicas completas de Sigmund Freud (vol. 14, pp. 249-263). Rio de Janeiro, RJ: Imago. (Trabalho original publicado em 1917[1915]).

Freud, S. (1996). Além do princípio de prazer (E. A. M. Souza, Trad.). In J. Salomão (Org.), Edição standard brasileira das obras psicológicas completas de Sigmund Freud (vol. 18, pp. 17-75). Rio de Janeiro, RJ: Imago. (Trabalho original publicado em 1920).

Freud, S. (1996). O problema econômico do masoquismo. (E. A. M. Souza, Trad.). In J. Salomão (Org.) Edição standard brasileira das obras psicológicas completas de Sigmund Freud (vol. 19, pp. 177-188). Rio de Janeiro, RJ: Imago. (Trabalho original publicado em 1924).

Freud, S. (1996). Inibições, sintomas e ansiedade (C. M. Oiticica, Trad). In J. Salomão (Org.), Edição standard brasileira das obras psicológicas completas de Sigmund Freud (vol. 20, pp. 91-170). Rio de Janeiro, RJ: Imago. (Trabalho original publicado em 1926).

Le Breton, D. (1995). Anthropologie de la douleur. Paris: Métailié.

Lima, M. A. G., \& Trad, L. (2008). Dor crônica: Objeto insubordinado. História, Ciências, Saúde Manguinhos, 15(1), 117-133. https://doi.org/10.1590/S0104-59702008000100007 
Lobato, O. (2010). O problema da dor. In J. Mello Filho \& M. Burd (Orgs.), Psicossomática hoje (pp. 235-254). $2^{\mathrm{a}}$ ed. Porto Alegre, RS: ArtMed.

Marty, P. (1976). Les mouvements individuels de vie et de mort. Paris: Payot.

Marty, P. (1993). A psicossomática do adulto (P. C. Ramos, Trad.). Porto Alegre, RS: Artes Médicas.

Pérez-Cajaraville, J. A., Abejón, D., Ortiz, J. R., \& Pérez, J. R. (2005). El dolor y su tratamiento a través de la historia. Revista de la Sociedad Española del Dolor, 12(6), 373-384.

Sabatowski, R., Schäfer, D., Kasper, S. M., Brunsch, H., \& Radbruch, L. (2004). Pain treatment: A historical overview. Current Pharmaceutical Design, 10(7), 701-716. https://doi.org/10.2174/1381612043452974

Task Force on Taxonomy of the International Association for the Study of Pain (1994). Classification of chronic pain: Descriptions of chronic pain syndromes and definitions of pain terms. Seattle: IASP Press.

Teixeira, M. J., \& Okada, M. (2009). Dor: Evolução histórica dos conhecimentos. In O. Alves Neto, C. M. C. Costa, J. T. T. Siqueira, \& M. J. Teixeira (Orgs.), Dor: Princípios e prática (pp. 27-56). Porto Alegre, RS: Artmed.

\section{CONFLITOS DE INTERESSES}

Não há conflitos de interesses.

\section{FINANCIAMENTO}

Conselho Nacional de Desenvolvimento Científico e Tecnológico (CNPq).

\section{SOBRE OS AUTORES}

Rodrigo Sanches Peres é psicólogo, mestre e doutor em Psicologia. Professor do Instituto de Psicologia e do Programa de Pós-Graduação em Psicologia da Universidade Federal de Uberlândia. Bolsista de Produtividade em Pesquisa do Conselho Nacional de Desenvolvimento Científico e Tecnológico.

E-mail: rodrigosanchesperes@ufu.br

(iD) https://orcid.org/0000-0002-2957-7554

Josiane Cristina Bocchi é psicóloga, mestre em Psicologia e doutora em Filosofia. Professora do Departamento de Psicologia da Faculdade de Ciências e do Programa de Pós-Graduação em Educação Sexual da Universidade Estadual Paulista "Júlio de Mesquita Filho".

E-mail: josiane.bocchi@unesp.br

(iD) https://orcid.org/0000-0002-2657-9490

1. Tipicamente, considera-se que a dor física se cronifica quando se estende por um período superior a três meses sem comprometimento orgânico que justifique tal processo.

2. Os títulos dos escritos freudianos citados no presente estudo acompanham a Edição standard brasileira das obras psicológicas completas de Sigmund Freud, a qual adotamos devido à sua ampla difusão no país. Porém, ao reportarmo-nos ao conteúdo dos mesmos, privilegiamos "pulsão" e "angústia" ao invés de "instinto" e "ansiedade" como tradução para os verbetes alemães trieb e angst, por uma questão de precisão conceitual.

3. Em geral, uma pessoa amada ou a abstração que ocupa seu lugar, conforme Freud (1996/1917[1915])

4. Ressalte-se que Marty prefere utilizar "traumatismo", ao invés de "trauma". 